\title{
INFLUENCE OF CHICKPEA SEEDING RATE ON PRODUCTIVITY IN DRY STEPPE VOLGA REGION
}

Phartukov Sergey Vladimirovich, Assistant of the chair "Crop Production, Selection and Genetics", Saratov State Agrarian University named after N.I. Vavilov. Russia.

Taspaev Nurlan Sultangalievich, Director, State Scientific Institution "Krasniy Kut Selection and Experimental Station", Agricultural Research Institute for South-East Region. Russia.

Germantseva Nadezhda Ivanovna, Doctor of Agricultural Sciences, Head of the laboratory of Selection of Leguminous Crops, State Scientific Institution "Krasniy Kut Selection Experimental Station", Agricultural Research Institute for South-East Region. Russia.

Shyurova Natalya Aleksandrovna, Candidate of Agricultural Sciences, Associate Professor, Head of the chair "Crop Production, Selection and Genetics", Saratov State Agrarian University named after N.I. Vavilov. Russia.

Narushev Viktor Bisengalievich, Doctor of Agricultural Sciences, Professor of the chair "Crop Production, Selection and Genetics", Saratov State Agrarian University named after N.I. Vavilov. Russia.

Keywords: chickpea; seeding rate; way of sowing; variety; chestnut soil; southern chernozem; area of leaves; dry biomass; photosynthesis; productivity.

The results of studies carried out in the experimental fields of the Saratov State Agrarian University and the Krasniy Kut Selection and Experimental Station on improvement of methods of zonal technology of chickpea cultivation are presented. The optimal seeding rates in the southern right-bank and central left-bank microzones of the Saratov region, in which the main crops of this culture are located, are established. When growing chickpeas in the southern microzone of the Saratov Right Bank, the highest yield of the variety Krasnokutskiy 36 was in the crops with inter-row spacing of $30 \mathrm{~cm}$ with a seeding rate of 0.6 million virgin seeds per 1 hectare - $1.66 \mathrm{t} / \mathrm{ha}$. In the central microzone of the Saratov Left bank region after ordinary method of sowing with interrow spacing of $15 \mathrm{~cm}$, the highest yield of the variety Krasnokutskiy 36 was at seeding rate of 0.8 million germinated seeds per $1 \mathrm{ha}-1.40 \mathrm{t} / \mathrm{ha}$; of the variety Zolotoy Yubiley at seeding rate of 0.7 million of seeds per hectare - $1.38 \mathrm{t} / \mathrm{ha}$; of the variety Vector at seeding rate of 0.6 million of the emergent seeds per 1 hectare - $1.26 \mathrm{t} / \mathrm{ha}$.

удК 632.7:470.44

\section{ВЛИЯНИЕ АНТРОПОГЕННОГО ФАКТОРА} НА ХИЩНЫХ ЭНТОМОФАГОВ В АГРОЦЕНОЗЕ ЯРОВОЙ ПШЕНИЦЫ В ПРАВОБЕРЕЖЬЕ САРАТОВСКОЙ ОБЛАСТИ

\author{
ЧЕКМАРЕВА Людмила Ивановна, Саратовский государственный аграрный \\ университет имени Н.И. Вавилова \\ ЛИХАЦКИЙ Дмитрий Михайлович, ООО «Потенциил» \\ ЛИХАЦКАЯ Светлана Геннадьевна, Министерство строительства и ЖКХ \\ Саратовской области
}

ТЕНЯЕВА Ольга Львовна, ООО «АгроСтройИнвест»

Определен видовой состав энтомофагов в агроценозах яровой пшенищы при современных технологиях обработки почв в Правобережъе Саратовской области. Установлены доминирующие виды хищных энтомофагов. Преобладали кокцинеллиды (отр. Coleoptera, сем. Coccinellidae) и пауки (отр. Агапеае), занимающие больще половины сообщества. Отмечены хищные трипсы (отр. Thysanoptera), златоглазки (отр. Neuroptera), жужелицы (отр. Coleoptera), муравъи (отр. Нутепорtеra), паразиты злаковых тлей (отр. Нутепорtеra, сем. Aphidiidae). Энергосберегающие технологии обработки почвы конщентрировали достаточное количество насекомых-энтомофагов, способньх регулировать иисленность вредителей. Увеличение видового состава энтомофагов в зависимости от обработки почвы происходит в ряду: вспашка $\rightarrow$ нулевая обработка $\rightarrow$ минимальная обработка. Численность самых эффективных энтомофагов пиенииных агроценозов (кокцинеллид и пауков) в зависимости от обработки почвы увеличивалась в ряду: нулевая обработка $\rightarrow$ вспашка $\rightarrow$ минимальная обработка.

Введение. В освоении научно обоснованных систем земледелия особое значение отводится системам обработки почвы, которые влияют на энергозатраты, плодородие почвы и урожайность возделываемых культур $[1,2]$.
Обработка почвы призвана благоприятствовать созданию оптимального сложения пашни, снижать испарение влаги с поверхности почвы, улучшать аккумуляцию осадков, предотвращать накопление сорняков, развитие 
болезней и вредителей при постоянном снижении затрат на ее проведение. Наибольший удельный вес среди всех затрат на возделывание сельскохозяйственных культур по традиционным технологиям приходится на обработку почвы [4].

Важные направления в защите растений поиск и разработка методов максимального сохранения, накопления и увеличения естественных ресурсов энтомофагов в регулировании численности вредных организмов.

Цель исследований заключалась в выявлении видового состава энтомофауны агроценозов яровой мягкой пшеницы при различной степени антропогенного воздействия на почву в Правобережье Саратовской области.

Методика исследований. Исследования проводили в 2012-2014 гг. на опытном поле Саратовского ГАУ им. Н.И. Вавилова. Схема опыта включала в себя три варианта основной обработки почвы: вспашку плугом на 23-25 см; минимальную обработку дисковой бороной на 10-12 см; нулевую обработку (без основной обработки). В контроле вспашку проводили плугом ПЛН-5-35; дискование - дисковой бороной Catros. Норма высева яровой мягкой пшеницы - 3,5 млн всхожих семян на 1 га.

Опыт проводили в четырехкратной повторности, площадь делянок 200 м². Размещение делянок рендомизированное. Учеты по выявлению видов насекомых при разных обработках почвы осуществляли в разные фазы вегетации яровой пшеницы по общепринятым методикам [5, 6].

Результаты исследований. В ходе работы по выявлению доминирующих видов энтомофагов при энергосберегающих обработках почвы в условиях Саратовского Правобережья были обследованы посевы яровой пшеницы сорта Фаворит. Изучение агроценоза зерновых культур при энергосберегающей технологии обработки почвы позволило выявить энтомофагов четырех отрядов хищных насекомых и отряд Пауки: хищные трипсы (отр. Thysanoptera - Бахромчатокрылые); златоглазки (отр. Neuroptera); жужелицы и кокциннелиды (отр. Coleoptera); муравьи (отр. Hymenoptera - Перепончатокрылые) и пауки (отр. Araneae).

В пшеничном агроценозе из энтомофагов с неполным превращением были отмечены хищные трипсы (сем. Aeolothripiae), доминировали два вида (Aeolothnps intermedius Bagn. u Aeolothrips fasciatus L.).Также в по- севах яровой пшеницы Фаворит нами отмечены златоглазки (отр. Neuroptera, сем. Chrysopidae), основные виды: обыкновенная - Chrysopa carnea S., 7-точечная Ch. Septempunctata Wesm., красивая - Ch. formosa B. Питались хризопы на посевах личинками фитофагов, уничтожая тлей, личинок младших возрастов пырейного клопика, личинок цикадок, яйца клопа-черепашки, пшеничных трипсов.

В течение вегетационного периода на посевах яровой пшеницы сорта Фаворит выявлено четыре доминирующих вида жужелиц: Pseudoohhonus melenarius L., Pseudoophonus rufipes Deg., Pterostichus crenuliger Chd. Pterostichus cupreus L. Более высокую численность жужелицы имеют на поле с использованием нулевой и минимальной технологии обработки почвы, что отрицательно влияет на плотность различных вредителей. Распространение многих видов жужелиц зависит прежде всего от абиотических факторов среды. Хищные жужелицы на полях яровой пшеницы играют значительную роль в комплексном использовании методов борьбы с вредителями.

К доминирующим видам в агроценозах яровой пшеницы Фаворит относятся представители отр. Coleoptera (сем. Coccinellidae), среди которых были выявлены три основых вида: коровка 7-точечная - Coccinella septempunctata L., 2-точечная - Adalia bipunctata L., коровка изменчивая - Adalia varieqata G. По данным исследований Л.И. Чекмаревой, С.Г. Лихацой, Д.М. Лихацкого и др. [3], пищевая активность кокцинеллид была довольно высокой, особенно личинок $(38,5-72,3$ экз. на 1 особь кокцинеллид), см. таблицу.

На вариантах с энергосберегающей технологией обработки почвы при увеличении численности фитофагов увеличилось и количество энтомофагов сем. Coccinellidae, способных регулировать численность вредителей.

В полевом агроценозе яровой пшеницы присутствовали муравьи сем. Formicidae, рыжий лесной муравей (Formica rufa) - вид с дневным типом активности и луговой муравей (Formica pratensis Rets.) - с утренне-вечерним типом.

В период исследований на пшеничных полях из паукообразных наибольшей численностью отличались представители сем. Salticidae, Agelenidae, Lycosidae, Thomisidae, Tetragnathidae, Araneidae (Araneus cornutus Cl.). Среди 
пауков, обитающих на поверхности почвы в агроэкосистемах пшеницы, наибольшее число видов относится к сем. Lycosidae и Linyphiidae.

В ходе исследований по выявлению видового состава энтомофагов пшеничного агроценоза в зависимости от агротехнологии возделывания культуры были также обнаружены паразиты злаковых тлей сем. Aphidiidae, виды Aphidius avenae Hal., A. ervi Hal., Praon volucre Hal., Ephedrus plagiator Ness. (доминирующие виды - Aphidius avenae и Aphidius ervi).

Учеты, проведенные на вариантах с минимальной и нулевой обработками в конце вегетации культуры, позволили установить, что численность фитофагов и энтомофагов была значительна, так как насекомые не покидали агроценозы перед зимовкой. Естественно, что в вариантах с энергосберегающей технологией обработки почвы при увеличении численности фитофагов выросло и количество насекомых-энтомофагов, способных регулировать численность вредителей.

В ходе исследований отмечали изменение видового состава и увеличение численности энтомофагов при снижении интенсивности обработки почвы в фазу кущения и молочной спелости яровой мягкой пшеницы. Энтомофауна пшеницы при разных обработках почвы представлена на рис. 1.

Доминирующие виды энтомофагов (кокцинеллиды и пауки) занимают больше половины сообщества в агроценозах при энергосберегающих технологиях обработки почвы. В фазу кущения при нулевой обработке было $50 \%$ имаго кокцинеллид, при минимальной $47 \%$ имаго и 20 \% личинок кокцинеллид (67 \% популяции хищных коровок от всех учтенных энтомофагов в варианте). На вспашке процентное соотношение имаго и личинок кокцинеллид составило 56 и 33 \% соответственно, т.е. 89 \% популяции кокцинеллид от всех учтенных энтомофагов в варианте.

Среди остальных представителей отмечены златоглазки, превалирующие при нулевой обработке почвы, - 15 \% в фазу кущения и 17 \% в фазу молочной спелости, при минимальной обработке - 13 и 7 \% соответственно; хищные трипсы при нулевой обработке - 15 \% в фазу кущения и 8 \% в фазу молочной спелости, при минимальной обработке $-15 \%$ в фазу молочной спелости, а также муравьи и жужелицы.

Оценивая эффективность энтомофагов, необходимо отмечать их активность в динамике в течение вегетации. Мы представили основной видовой состав выявленных энтомофагов на яровой мягкой пшенице в фазы кущения, трубкования и восковой спелости при разных обработках почвы.

Эколого-трофическую нишу заполнили виды кокцинеллид с фазы кущения пшеницы до восковой спелости, которые активно поедали фитофагов (рис. 2).

Пауки также заселяли агроценоз с фазы трубкования до конца вегетации как типично многоядные хищники, их численность нарастала постепенно, с увеличением трофической базы, хотя видовой состав жертв менялся в зависимости от фазы развития пшеницы. В отличие от коровок и пауков, муравьи проявляли активность в основном в первую половину вегетации.

Тлевые наездники (афидииды) - специализированные паразиты злаковых тлей, были обнаружены в массе только в вариантах с основной обработкой - вспашкой, в фазу выхода в трубку пшеницы, когда их хозяева (тли) имели наибольшую численность.

Нулевая обработка почвы (рис. 3) способствовала накоплению наибольшего видового разнообразия (златоглазки, хищные трипсы, коровки, жужелицы и пауки), отсутствовали муравьи - приземные хищники.

Жужелицы были активны в основном в фазу трубкования. Златоглазки как насекомые требовательные к умеренной температуре и влажности воздуха присутствовали в фазы кущения до выхода в трубку яровой мягкой пшеницы, далее, очевидно, мигрировали на сорную растительность

Пищевая активность кокцинеллид (сем. Cоccinellidae) в пшеничном агроценозе (2013 г.)

\begin{tabular}{|l|c|c|}
\hline \multirow{2}{*}{ Вид энтомофага (хищника) } & \multicolumn{2}{|c|}{ Средняя численность тлей, поедаемых коровками, экз./сут. } \\
\cline { 2 - 3 } & имаго & личинки \\
\hline Coccinella septempunctata L. & $54,1 \pm 3,4$ & $72,3 \pm 3,9$ \\
\hline Adalia bipunctata L. & $40,4 \pm 1,8$ & $38,5 \pm 2,6$ \\
\hline
\end{tabular}


обочин дорог, лесополосы и другие стации.

Кокцинеллиды и пауки присутствовали, как и в варианте со вспашкой, в значительном количестве, занимая доминирующее положение в агроценозе. Минимальная обработка почвы (рис. 4), так же как нулевая, привела к накоплению достаточного количества энтомофагов, в частности кокцинеллиды и пауки были зафиксированы в энтомологических сборах в течение всего периода вегетации яровой мягкой пшеницы.

Златоглазки присутствовали в первую половину вегетации, в фазу трубкования превосходили по численности кокцинеллид. В этот же период в агроценозе присутствовали муравьи, которые активно питались в ниженем ярусе.

При минимальной и нулевой обработках почвы происходило накопление энтомофагов за счет кормовой базы и условий перезимовки.

Заключение. Среди представителей энтомофагов преобладали кокцинеллиды (Coleoptera, Coccinellidae) и пауки (Araneae), занимающие больше половины сообщест-
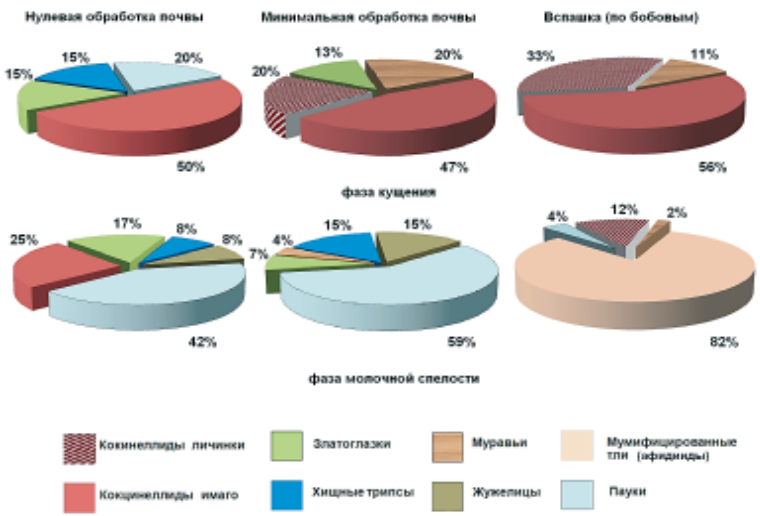

Рис. 1. Соотношение видового состава энтомофагов в агроценозе яровой мягкой пшенищы при разных приемах обработки почвы

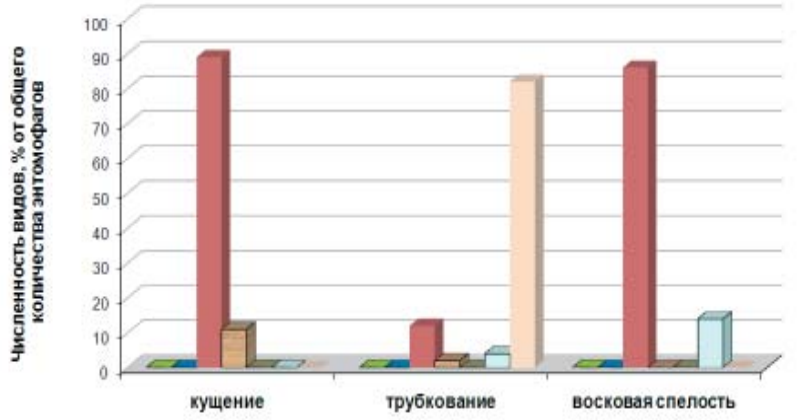

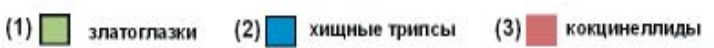
$\begin{array}{llll}\text { (4) } \square \text { муравьи } & \text { (5) } \square \text { жужелицы } & \text { (6) } \square \text { пауки } & \text { (7) } \square \text { афидииды }\end{array}$

Рис. 2. Энтомофаги яровой мягкой пшеницы при вспашке (фазы кущение восковая спелость) ва. Среди остальных представителей отмечены златоглазки (Neuroptera, Chrysopidae), хищные трипсы (Thysanoptera, Aeolothripidae), муравьи (Hymenoptera, Formicidae) и жужелицы (Coleoptera, Carabidae). Этим не исчерпывается разнообразие энтомофауны яровой пшеницы, но эти виды составляют основное ядро, которое отличается относительной стабильностью.

Обобщая данные учетов и анализируя видовой состав полезных насекомых в агроценозе яровой мягкой пшеницы, на фоне классической обработки почвы плугом (вспашка) в условиях Саратовского Правобережья, отмечали практически полное отсутствие некоторых групп хищных энтомофагов, таких как хищные трипсы, златоглазки, и жужелицы. Оценивая эффективность энтомофагов, необходимо учитывать их активность в динамике на сельскохозяйственных культурах в течение вегетации. Отсутствие обработки почвы благоприятствовало сохранению экологического равновесия энтомофауны в агроценозах.

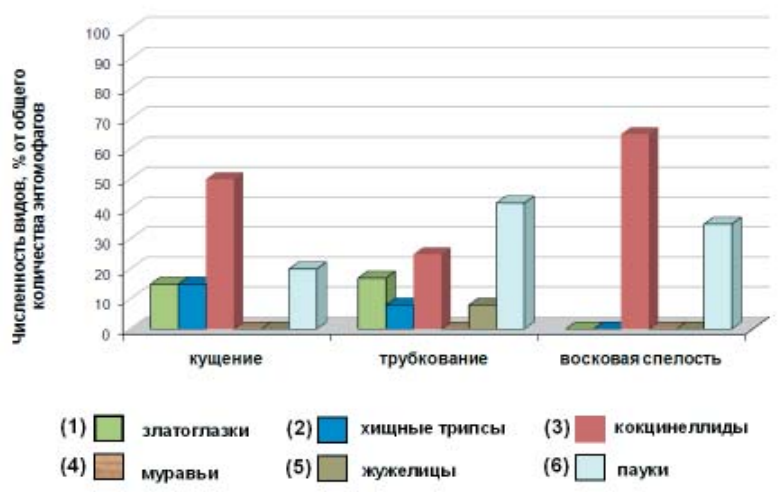

Рис. 3. Энтомофаги яровой мягкой пшенищы при нулевой обработке (фазы кущение - восковая спелость)

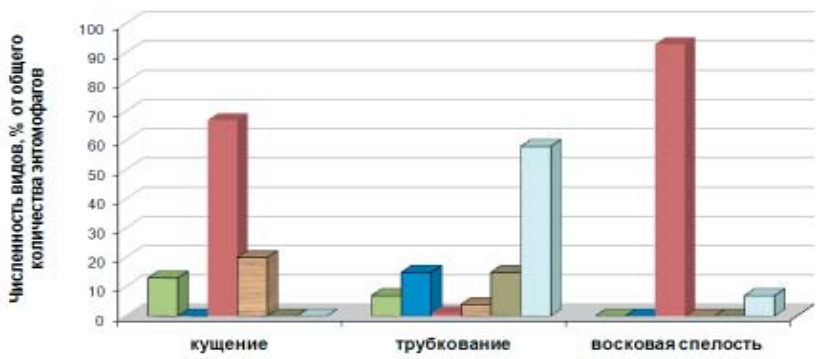
(1) $\square$ златоглазки
(2) $\square$ хищные трипсы
(3) кокцинеллиды
(4) $\square$ муравьи
(5) $\square$ жужелицы
(6) $\square$ пауки

Рис. 4. Энтомофаги яровой мягкой пшеницы при минимальной обработке (фазы кущение восковая спелость) 
Увеличение энтомофагов в посевах яровой мягкой пшеницы при вышеуказанных приемах обработки почвы максимально сдерживало численность вредителей, поэтому их количество не превышало порогов вредоносности. По данным исследований 2012-2014 гг., в условиях Саратовской области с применением новых энергосберегающих технологий изменяются микроклиматические условия в агроценозах и создаются более благоприятные условия для развития и питания энтомофагов.

Увеличение видового состава энтомофагов в зависимости от обработки почвы происходит в ряду: вспашка $\rightarrow$ нулевая обработка $\rightarrow$ минимальная обработка. Численность самых эффективных энтомофагов пшеничных агроценозов (кокцинеллид и пауков) в зависимости от обработки почвы увеличивалась в ряду: нулевая обработка $\rightarrow$ вспашка $\rightarrow$ минимальная обработка. Минимальная обработка и вспашка снижали численность вредителей, повышали компенсаторные способности яровой пшеницы и активность энтомофагов.

\section{СПИСОК ЛИТЕРАТУРЫ}

1. Азизов 3.М. Оптимизация системы основной обработки почвы в зернопаровом севообороте засушливой черноземной степи Поволжья: дис. ... канд. с.-х. наук. - Саратов, 2006. - 477 с.

2. Влияние интенсивности обработки почвы на численность вредителей в посевах яровой пшеницы / Е.П. Денисов [и др.] // Аграрный научный журнал. - 2016. - № 6. - С. 8-14.
3. Изменение элементов агроценоза пшеницы под влиянием обработки почвы / Л.И. Чекмарева [и др.] // Известия Оренбургского государственного аграрного университета. - 2015. - № 3 (53). C. $20-22$.

4. Карпец В.В. Эффективность энергосберегающих обработок почвы при возделывании ячменя на черноземах южных Поволжья: автореф. дис. ... канд. с.-х. наук. - Саратов, 2015. - 21 с.

5. Осмоловский Г.Е. Выявление сельскохозяйственных вредителей и сигнализация сроков борьбы с ними. - М.: Россельхозиздат, 1964. - С. 18-27.

6. Палий В.Ф. Методика изучения фауны и фенологии. - 2-е изд., испр. и доп. - Воронеж, 1970. - 190 c.

Чекмарева Людмила Ивановна, $\partial-p c .-x$. наук, проф. кафедры «Растениеводство, селекиия и генетика», Саратовский государственный аграрный университет имени Н.И. Вавилова. Россия.

410012, г. Саратов, Театральная пл., 1.

Тел.: (8452) 26-16-28.

Лихацкий Дмитрий Михайлович, канд. с.-х. наук, зам. управляющего, ООО «Потенциал». Россия.

410012, г. Саратов, ул. Артиллерийская, 2.

Тел.: 9271452390.

Лихацкая Светлана Геннадьева, канд. с.-х. наук, Министерство строительства и ЖКХ Саратовской области. Россия.

410012, г. Саратов, ул. Челюскинцев, 114.

Тел.; (8452) 27-77-91.

Теняева Ольга Львовна, канд. с.-х. наук, научный консультант, ООО «АгроСтройИнвест». Россия.

410049, г. Саратов, Новоастраханское шоссе, 80.

Тел.: 89053673393.

Ключевые слова: яровая пшенииа; агроценоз; энтомофаги, кокиинеллиды; пауки; златоглазки; хищные трипсы; муравьи.

\section{INFLUENCE OF THE ANTHROPOGENIC FACTOR ON THE PREDATORY ENTOMOPHAGES IN AGROCENOSE OF Spring WHEAT IN THE RIGHT BANK OF THE SARATOV REGION}

Chekmareva Lyudmila Ivanovna, Doctor of Agricultural Sciences, Professor of the chair "Crop Production, Selection and Genetics", Saratov State Agrarian University named after N.I. Vavilov. Russia.

Likhatskiy Dmitriy Mykhaylovich, Candidate of Agricultural Sciences, Deputy Manager, OOO "Potential". Russia.

Likhatskaya Svetlana Gennadyevna, Candidate of Agricultural Sciences, Ministry of Building and Housing and Public Utilities of the Saratov Region. Russia.

Tenyaeva Olga Lvovna, Candidate of Agricultural Sciences, Scientific Adviser, OOO “AgroStroiInvest”. Russia.

Keywords: spring wheat; agrocenosis; entomophages, coccinellids; spiders; lion aphids; predatory thrips; ants.

Species composition of entomophages in agrocenoses of spring wheat at modern soil treatment technologies in the Right Bank of the Saratov Region is determined. The dominant species of predatory entomophages are established. Coccinellids (Coleoptera, Coccinellidae) and spiders (Araneae), occupying more than half of the community predominated. Predatory thrips (Thysanoptera), lion aphids (Neuroptera), beetles (Coleoptera), ants (Hymenoptera), parasites of cereal aphids (Hymenoptera, Aphidiidae) are marked. Energy-saving technologies of soil cultivation concentrated a sufficient number of insect-entomophages capable for regulating the number of pests. The increase in the species composition of entomophages depending on the soil cultivation takes place at the following treatment: plowing $\rightarrow$ zero processing $\rightarrow$ minimal processing. The number of the most effective entomophages of wheat agrocenoses (coccinellids and spiders), depending on soil cultivation, increased after zero tillage $\rightarrow$ plowing $\rightarrow$ minimal tillage. 